\title{
Impacts of Dissolved Oxygen and Initial Sludge Concentrations on Aerobic Stabilization of Sewage Sludge
}

\author{
Bin Ji ${ }^{1 *}$, Kai Yang ${ }^{2}$, Wei Chen ${ }^{1}$, Jian Wang ${ }^{1}$, Lei Zhu ${ }^{1}$ \\ 'School of Urban Construction, Wuhan University of Science and Technology, \\ Wuhan 430065, China \\ ${ }^{2}$ School of Civil Engineering, Wuhan University, \\ Wuhan 430072, China
}

Received: 19 September 2015

Accepted: 28 September 2015

\begin{abstract}
Impacts of dissolved oxygen (DO) and initial sludge concentrations on aerobic digestion for sewage sludge treatment were studied without adding alkalis. The MLVSS removal efficiencies were $50 \%$ and $47 \%$ in 20 days when DO concentrations were about 5.0 and $7.0 \mathrm{mg} / \mathrm{L}$, respectively. Value of $\mathrm{pH}$ increased slightly in the first 6 days and then dropped constantly. The decrease of MLVSS appeared first quick back slow trend during the process and the OUR declination was similar. At the same DO level of $5.0 \mathrm{mg} / \mathrm{L}$, the lower initial sludge concentration favored the efficiency of sludge stabilization. Both TN and TP of the supernatant were continually increasing and the ultimate concentrations were three to four times the initial concentrations. Results obtained from the present work could provide basic information for the aerobic sludge treatment process.
\end{abstract}

Keywords: sewage sludge treatment, aerobic digestion, sludge stabilization, oxygen uptake rate

\section{Introduction}

A current major waste disposal issue revolves around the disposal of excess activated sludge generated during wastewater treatment due to the expansion of municipal wastewater treatment and increasingly stringent regulations. Sludge stabilization is a key step for sewage sludge treatment. The most common methods of sludge stabilization are biological processes of anaerobic digestion and aerobic digestion. Anaerobic digestion is a biological process in which the organic matter is degraded in the absence of oxygen, and gasses such as methane and ammonia are generated [1]. While under aerobic

*e-mail: binji@wust.edu.cn conditions organic matter is oxidized and products such as carbon dioxide, nitrate or phosphate are generated. Both anaerobic digestion and aerobic digestion are the utilization of microorganisms to degrade various organic compounds.

Aerobic digestion conducted by aerobic organisms is usually applied in small- and medium-sized wastewater treatment plants, due to its low capital cost and simple operation [2]. At treatment plants with a design flow capacity of less than $20,000 \mathrm{~m}^{3} \mathrm{~d}^{-1}$, aerobic digestion would appear to be the best environmental option for sludge stabilization [3]. The modified methods of aerobic digestion include autothermal thermophilic aerobic digestion [4], some pre-treatments [5], and some hybrid methods [6]. These methods could be promising modifications for reducing sludge production in household 
wastewater treatment systems. Despite the application of aerobic sludge digestion being widespread with various modified methods being exploited, the basic process of aerobic digestion has not been reported.

In the present paper, aerobic digestion based on sewage sludge was investigated over 40 days. The variations of mixed liquor volatile suspended solids (MLVSS), $\mathrm{pH}$ values, and OUR (oxygen uptake rate) were monitored during the whole phase. Impacts of DO (dissolved oxygen) concentrations and initial sludge concentrations on aerobic digestion were studied. Moreover, nitrogen and phosphorus concentrations of the supernatant generated during digestion were also monitored. Results obtained from the present work could provide basic information for the aerobic sludge treatment process.

\section{Materials and Methods}

The excess activated sludge used in this study was obtained from the outlet of the aeration tank of Shahu Wastewater Treatment Plant, Wuhan, China. The gravity thickening method was applied to increase the sludge concentration. The aim of gravity thickening processes is to increase the solids concentration of particulate slurries. Gravity thickening depends on the difference in densities between the solid and liquid phases [7]. After $10 \mathrm{~h}$ of thickening, the supernatant was collected, which was used for different concentrations of sludge. The sludge was aerated for $12 \mathrm{~h}$ to exhaust the exogenous carbon source before experiments.

The experiment extended for 40 days using four labscale SBRs, with $6.5 \mathrm{~L}$ working volume and $5 \mathrm{~L}$ effective volume. The reactors were equipped with mixing and aeration equipment. Different oxygen concentrations were acquired using air control valves. The DO concentrations during the aerobic treatment were maintained at about 3.0, 5.0, 7.0, and $9.0 \mathrm{mg} / \mathrm{L}$, respectively. This procedure was extended for 20 days. On day No. 20, different concentrations of sludge were studied for aerobic digestion when DO concentration was about $5.0 \mathrm{mg} / \mathrm{L}$. Nitrogen and phosphorus concentrations of the supernatant generated during digestion were also monitored. The tests were operated in an air-conditioning room at $23-27^{\circ} \mathrm{C}$.

Total nitrogen (TN), total phosphorus (TP), sludge water content, and mixed liquor volatile suspended solids (MLVSS) of the samples were determined according to the Standard Methods [8]. Water $\mathrm{pH}$ was measured by an 828 Orion $\mathrm{pH}$ meter while dissolved oxygen (DO) and water temperature were measured with a YSI550A DO meter. OUR was measured [9]. Values are presented as means $(n=3)$.

\section{Results and Discussion}

Impact of DO Concentration on Aerobic
Digestion of Sludge

\section{MLVSS Variation}

MLVSS variation in the four reactors is reflected in Fig. 1A. The MLVSS decreased 2850, 4051, 5176, and

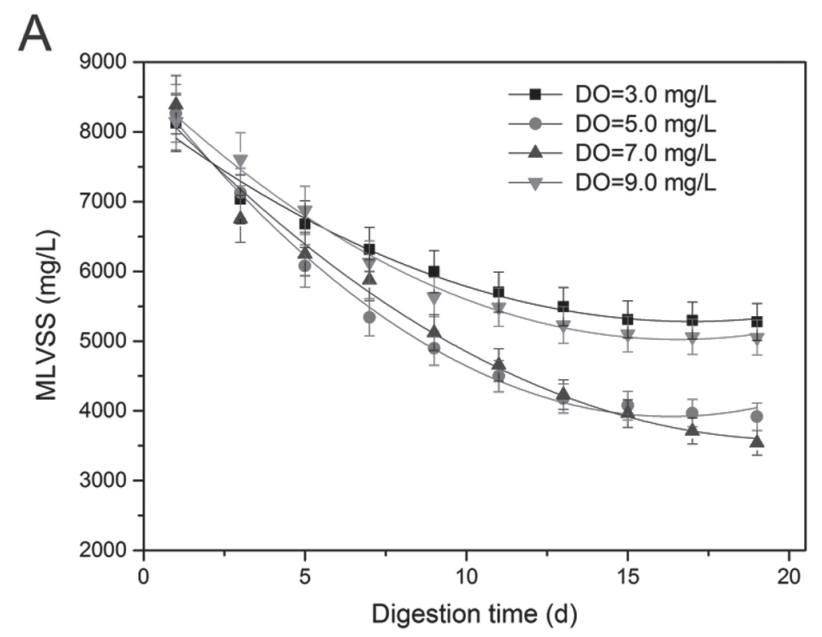

B
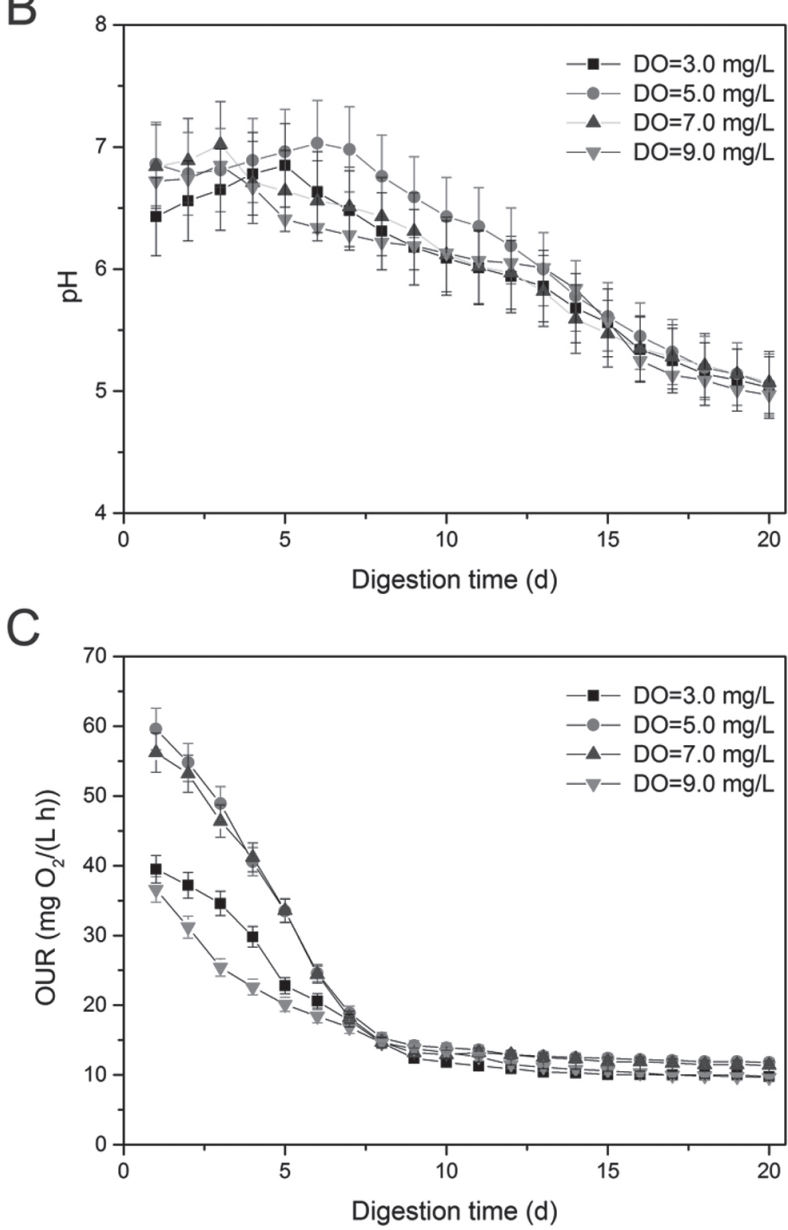

Fig. 1. Variations of sludge characteristics at different DO levels: (A) MLVSS, (B) $\mathrm{pH}$, (C) OUR. 
$3096 \mathrm{mg} / \mathrm{L}$ when DO concentrations were 3.0, 5.0, 7.0, and $9.0 \mathrm{mg} / \mathrm{L}$, respectively. It was suggested that the aerobic digestion could be inhibited when DO concentrations were too low or too high. The oxygen was relatively insufficient for the microorganisms to conduct aerobic digestion when DO concentration was $3.0 \mathrm{mg} / \mathrm{L}$. An increase in the DO concentration from 1.0 to $7.0 \mathrm{mg} / \mathrm{L}$ resulted in a significant increase in degradation rates of total solids as well as total volatile solids [10]. When DO concentration was $9.0 \mathrm{mg} / \mathrm{L}$, the aerobic microorganisms could also be inhibited on account of free radicals produced by excessive oxygen, which could damage cells [11]. Hence, DO concentrations varying from 5.0 to $7.0 \mathrm{mg} / \mathrm{L}$ were proper for aerobic sludge treatment.

\section{Variation of $p H$ Value}

During the study, $\mathrm{pH}$ value was varied without alkalis supplemented. Variation of $\mathrm{pH}$ (Fig. 1B) reflected the degradation of MLVSS and two important biological processes were ammonification and nitrification. In most cases, $\mathrm{pH}$ values increase slightly in the first 6 days due to the dominant ammonification process, which could
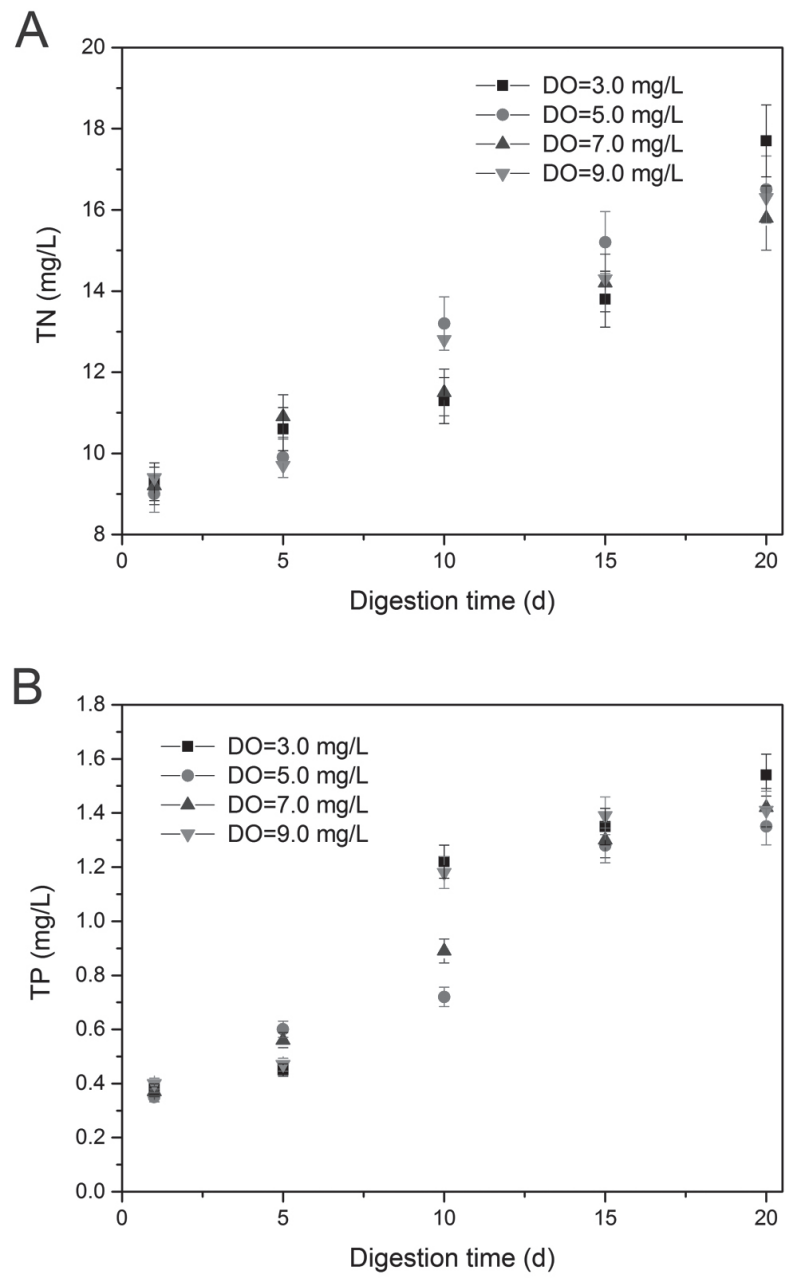

Fig. 2. Characteristics of the supernatant at different DO levels: (A) TN, (B) TP. contribute to alkali formation. After 6 days, most ammonia generated and the dominant nitrification process resulted in the steady declination of $\mathrm{pH}$ value. Moreover, after day 16 the curves tend to be mild and stable, which indicated that the MLVSS degradation under aerobic conditions was completed in almost 15 days.

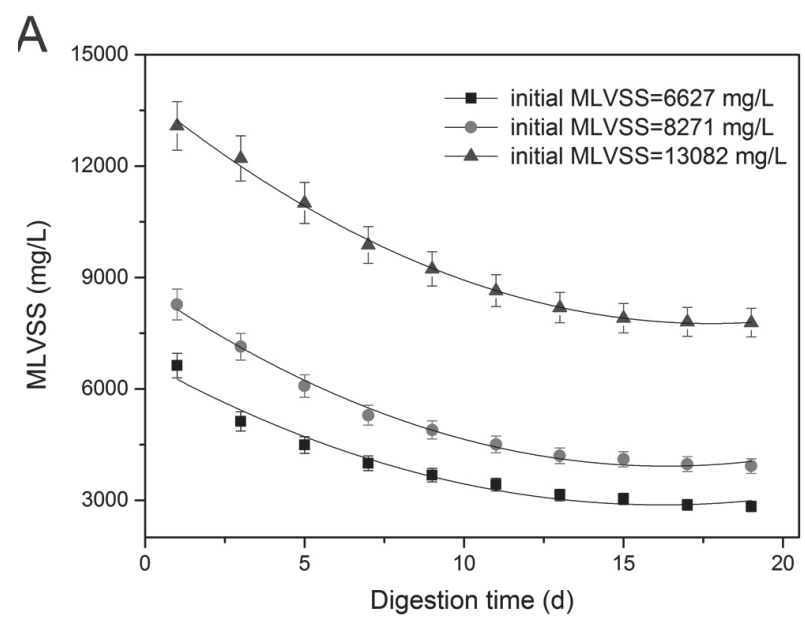

B
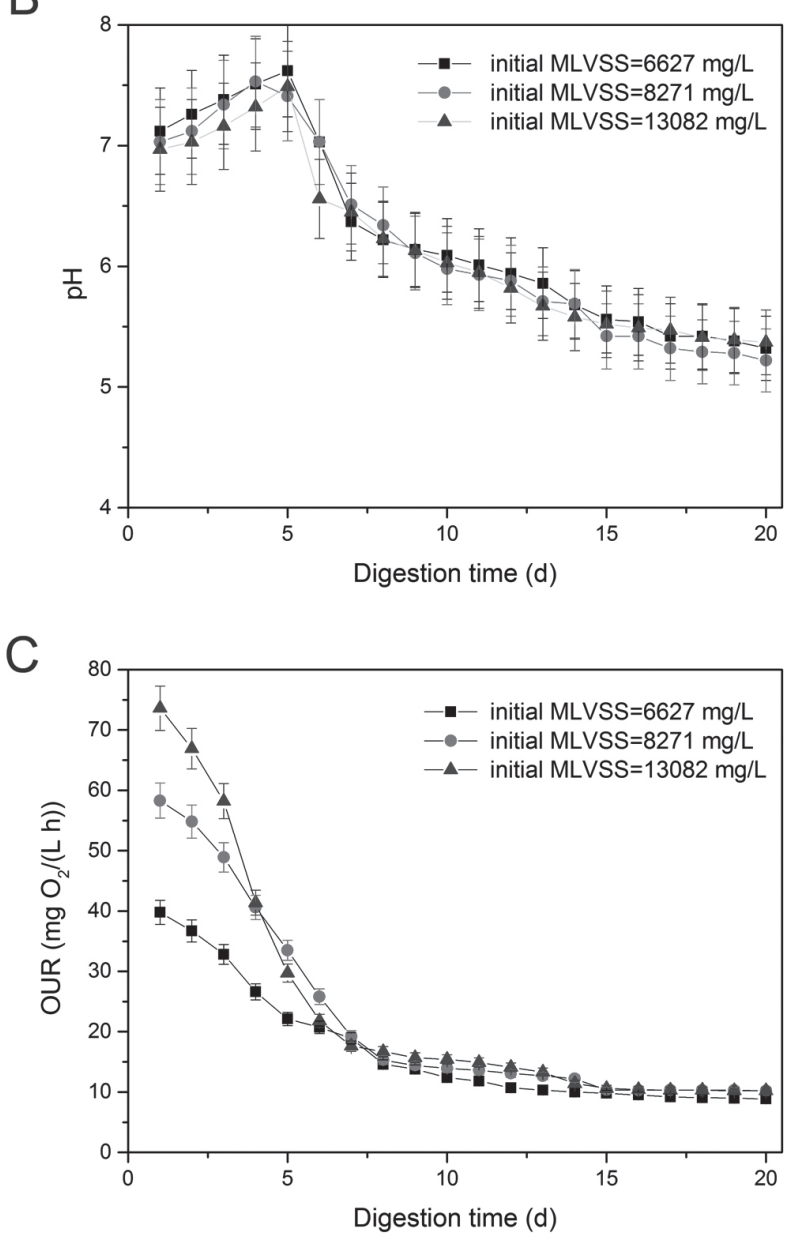

Fig. 3. Variations of sludge characteristics with different initial MLVSS: (A) MLVSS, (B) pH, (C) OUR. 


\section{Variation of OUR}

Oxygen utilization rate gives an indication of microbial activity because micro-organisms convert $\mathrm{O}_{2}$ to $\mathrm{CO}_{2}$ during biodegradation of organic matter. As shown in Fig. 1C, the initial OUR was the highest when DO concentration was $5.0 \mathrm{mg} / \mathrm{L}$, suggesting that the aerobic microorganism tends to be most active at this DO level. Moreover, the OUR declined quickly when DO was 5.0 and $7.0 \mathrm{mg} / \mathrm{L}$. It demonstrated again that DO concentrations at 5.0 to $7.0 \mathrm{mg} / \mathrm{L}$ were proper for aerobic sludge treatment.

\section{Variations of TN and TP of the Supernatant}

The variations of $\mathrm{TN}$ and $\mathrm{TP}$ of the supernatant generated during the aerobic digestion are presented in Fig. 2. Both TN and TP of the supernatant were continually increasing and the ultimate concentrations were three to four times the initial concentrations. The increase of nitrogen and phosphorus could be ascribed to the endogenous metabolism of the microbes. The ultimate TN and TP were about $17.0 \mathrm{mg} / \mathrm{L}$ and $1.4 \mathrm{mg} / \mathrm{L}$, respectively, when DO concentrations varied. The supernatant generated during aerobic digestion should be treated.

\section{Impacts of Initial Sludge Concentrations}

\section{MLVSS Variation}

MLVSS variations of activated sludge in the three reactors are reflected in Fig. 3A, which indicates that the removal of MLVSS increased with the larger initial sludge concentration, but that the removal efficiency of MLVSS decreased with the larger initial sludge concentration. The removal efficiencies of MLVSS were $57.2 \%, 52.6 \%$, and $40.5 \%$, respectively, when the initial MLVSS were about $6,627,8,271$, and $13,082 \mathrm{mg} / \mathrm{L}$. The reason was that the larger initial sludge concentration has a higher concentration of substance to degrade. But when the initial sludge concentration was high, sludge particles could aggregate into large flocs, thus preventing the transfer of oxygen. At the same DO level of $5.0 \mathrm{mg} / \mathrm{L}$, the lower initial sludge concentration favored the efficiency of sludge stabilization. Therefore, the initial sludge concentration was a vital factor for engineering practice. We should enhance the DO concentration when the initial MLVSS was relatively high in order to get a better result.

\section{Variations of $\mathrm{pH}$ Value and OUR}

As depicted in Fig. 3B, the pH values increase slightly and then drop to form stable curves. The $\mathrm{pH}$ values were dropped to about 5.5 on day 15 , suggesting the aerobic reactions were almost completed. It was reported that sludge digestion at $\mathrm{pH} 7.0$ was more efficient than at other $\mathrm{pH}$ values [12]. But our work demonstrated that the sludge stabilization at DO concentration of $5.0 \mathrm{mg} / \mathrm{L}$ achieved good effect, without any alkalis supplemented.
Fig. 3C indicates that the OUR declines continually during the whole process. The OUR dropped quickly in the first 10 days and then became mild in the later 10 days, which were similar to the variations of MLVSS. The high initial sludge concentration favored the initial OUR. The reason was that the high initial sludge owned a large quantity of microorganisms. Furthermore, the initial MLVSS in the experiment would be not important for OUR when the digestion time was more than 10 days.

\section{Variations of TN and TP of the Supernatant}

Variations of TN and TP of the supernatant are presented in Fig. 4, which indicates that both TN and TP kept growing up during the process and had a trend to continue growing. The higher the initial sludge concentration was, the higher the concentrations of TN and TP of the supernatant were. The supernatant generated by aerobic digestion on day 20 were just similar to the influent of the Shahu Wastewater Treatment Plant as for TN and TP, which were about $17 \mathrm{mg} / \mathrm{L}$ and $1.4 \mathrm{mg} / \mathrm{L}$ on average, respectively.
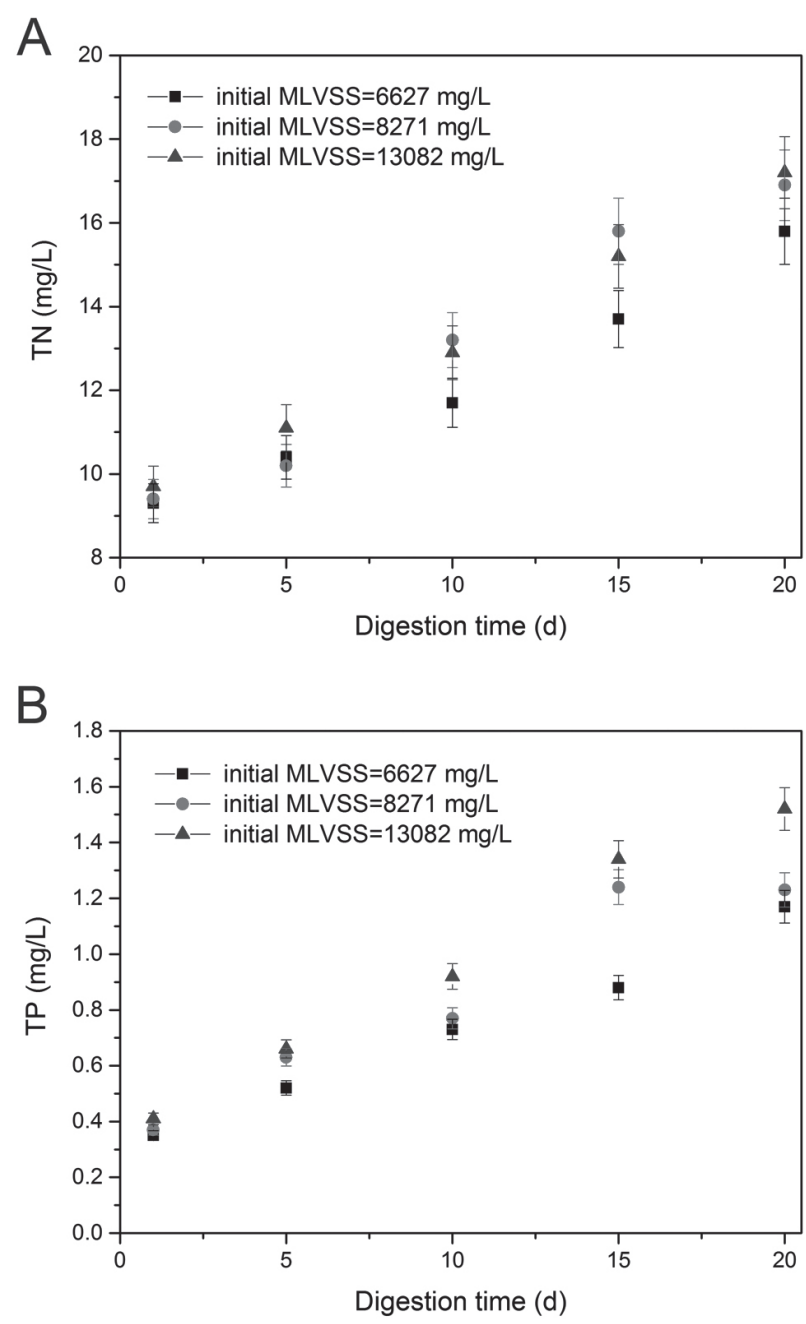

Fig. 4. Characteristics of the supernatant with different initial MLVSS: (A) TN, (B) TP. 


\section{Sludge Disposal}

Sludge incineration is a frequently employed disposed method but it harms the environment with the discharge of hazardous gases. One environmentally friendly method is the sanitary landfill method. As the digested domestic sludge contains no toxic materials but quite high acidity, it may be buried in an area of alkali soil. The digested domestic sludge may also be used as fertilizer in the area of alkali soil to grow trees and crops. Moreover, the sludge can also be used as a raw material to build concrete blocks by using of stabilization/solidification process [13]. More methods need to be exploited to cope with the aerobic digested sludge.

\section{Conclusion}

The excessive sludge of domestic wastewater was tested for aerobic digestion. The MLVSS removal efficiencies were $50 \%$ and $47 \%$ at DO concentrations of 5.0 and $7.0 \mathrm{mg} / \mathrm{L}$, respectively, in 20 days. More than $90 \%$ of MLVSS removal was completed in 15 days. The $\mathrm{pH}$ values increase slightly and then drop. At the same DO level of $5.0 \mathrm{mg} / \mathrm{L}$, the lower initial sludge concentration favored the efficiency of sludge stabilization. The supernatant generated during the aerobic digestion should be treated.

\section{Acknowledgements}

This research was financially supported by the open fund of State Key Lab of Urban Water Resources and Environment (HIT) (No. QAK201014) and the National Science and Technology Pillar Program (Nos. 2014BAL04B04 and 2015BAL01B02). We also thank the support of Wuhan University of Science and Technology No. 100192.

\section{References}

1. MARTÍN J., SANTOS J.L., APARICIO I., ALONSO E. Pharmaceutically active compounds in sludge stabilization treatments: Anaerobic and aerobic digestion, wastewater stabilization ponds and composting. Science of the Total Environment, 503, 2015.
2. LIU S., ZHU N., LI L.Y. The one-stage autothermal thermophilic aerobic digestion for sewage sludge treatment: Stabilization process and mechanism. Bioresource Technology, 104, 2012.

3. BERNARD S., GRAY N.F. Aerobic digestion of pharmaceutical and domestic wastewater sludges at ambient temperature. Water Research, 34, 3, 2000.

4. HAYES D., IZZARD L., SEVIOUR R. Microbial ecology of autothermal thermophilic aerobic digester (ATAD) systems for treating waste activated sludge. Systematic and Applied Microbiology, 34, 2, 2011.

5. SONG L., ZHU N., YUAN H., HONG Y., DING J. Enhancement of waste activated sludge aerobic digestion by electrochemical pre-treatment. Water Research, 44, 15, 2010.

6. ICHINARI T., OHTSUBO A., OZAWA T., HASEGAWA K., TEDUKA K., OGUCHI T., KISO Y. Wastewater treatment performance and sludge reduction properties of a household wastewater treatment system combined with an aerobic sludge digestion unit. Process Biochemistry, 43, 7, 2008.

7. USHER S.P., SPEHAR R., SCALES P.J. Theoretical analysis of aggregate densification: Impact on thickener performance. Chemical Engineering Journal, 151, 1, 2009.

8. APHA A.W. Standard methods for the examination of water and wastewater. Washington D.C,USA: American Public Health Association, 2005.

9. GANESH R., BALAJI G., RAMANUJAM R.A. Biodegradation of tannery wastewater using sequencing batch reactor - Respirometric assessment. Bioresource Technology, 97, 15, 2006.

10. FILALI-MEKNASSI Y., TYAGI R.D., NARASIAH K.S. Simultaneous sewage sludge digestion and metal leaching: effect of aeration. Process Biochemistry, 36, 3, 2000.

11. AHLBERG S., MEINKE M.C., WERNER L., EPPLE M., DIENDORF J., BLUME-PEYTAVI U., LADEMANN J., VOGT A., RANCAN F. Comparison of silver nanoparticles stored under air or argon with respect to the induction of intracellular free radicals and toxic effects toward keratinocytes. European Journal of Pharmaceutics and Biopharmaceutics, 88, 3, 2014.

12. UGWUANYI J.O., HARVEY L.M., MCNEIL B. Effect of digestion temperature and $\mathrm{pH}$ on treatment efficiency and evolution of volatile fatty acids during thermophilic aerobic digestion of model high strength agricultural waste. Bioresource Technology, 96, 6, 2005.

13. SILVA M.A., MATER L., SOUZA-SIERRA M.M., CORREA A.X., SPERB R., RADETSKI C.M. Small hazardous waste generators in developing countries: use of stabilization/solidification process as an economic tool for metal wastewater treatment and appropriate sludge disposal. Journal of Hazardous Materials, 147, 3, 2007. 
